\title{
Green Mark Super Low Energy Building: A Singapore Campus Case Study
}

\author{
M.A. Sarwar ${ }^{1}$, C.C. Lee $^{1}$ \\ ${ }^{1}$ Newcastle Australia Institute of Higher Education, Singapore. \\ charles.cc.lee@newcastle.edu.au
}

\section{Extended Abstract}

Singapore's Building Construction Authority's (BCA) Green Mark Scheme, started in 2005, is an initiative to create a sustainable built environment by promoting sustainable design, and best practices in construction and operations in buildings. To date, over 4,000 buildings in Singapore have met the BCA Green Mark standards covering 123 million square meters, which is more than $43 \%$ of the total floor area of Singapore's building stock. In 2021, an updated version, BCA Green Mark 2021, was introduced raising the built environment's sustainability standards such as: designing for maintainability; reducing embodied carbon across a building's life cycle; using smart technologies; enhancing resistance to climate change; and creating healthier environments. Besides buildings consuming about a third of the total energy budget in Singapore, it is also a major contributor of carbon emissions. These challenges pose a great opportunity for BCA's aspiration to achieve Positive Energy, Zero Energy and Super Low Energy Buildings (known as Super Low Energy, SLE) that are 60-80\% more energy efficient over 2005 levels.

This paper presents a summary of the strict requirements to achieve a Green Mark (GM) SLE status. Additionally, a case study of a Jurong office campus that is designed to meet GM SLE standards with the highest category of Green Mark Platinum will be presented. The development will include features such as: leveraging Building Information Modelling (BIM) and extending it to a comprehensive Integrated Digital Delivery; utilizing solar photovoltaic technology which will yield $340 \mathrm{MWH}$ of renewable energy annually; integrating rain gardens and bio-swales to enhance water sustenance; enhancing green technologies including smart lighting control, underfloor air-distribution systems, and predictive smart building control systems. This important project will assist to meet three (3) important UN Sustainable Development Goals: SDG 7 (affordable and clean energy); SDG 11 (sustainable cities and communities); SDG 13 (climate action). 